\title{
Shaping the future of dental education: Caries as a case-study
}

\author{
N. B. Pitts ${ }^{1}$ | M. E. Mazevet ${ }^{2}$ | C. Mayne ${ }^{3}$ On behalf of the Shaping the Future of \\ Dental Education Cariology Group ${ }^{\dagger}$
}

${ }^{1}$ Dental Innovation and Translation Centre (DITC), Kings College London Dental Institute, Guy's Hospital, London, UK ${ }^{2}$ Dental Innovation and Translation centre (DITC), Kings College London Dental Institute, London, UK

${ }^{3}$ The Alliance for a Cavity-Free Future, King's College London Dental Institute, London, UK

\section{Correspondence}

Nigel B. Pitts, Dental Innovation and Translation Centre (DITC), Kings College London Dental Institute, Guy's Hospital, London, UK.

Email: nigel.pitts@kcl.ac.uk

\begin{abstract}
This study reports on the full-day workshop "The Shape of The Future of Dental Education for Dental Caries-and how we get there" held immediately prior to the May 2017 ADEE/ADEA/King's College London meeting "Shaping the Future of Dental Education." A standardised, evidence-led Core Curriculum in Cariology (CCC) was developed jointly and systematically by ORCA and ADEE, starting in 2010. At the same time, the ICDAS Foundation was developing a comprehensive caries management system, ICCMS ${ }^{\mathrm{TM}}$. The workshop reported on what has been achieved on a global basis by many building on these initiatives. The CCC has been, or is currently being, localised in a number of places around the world and has, in some countries, been successfully implemented. There are also other areas which are struggling more with the logistics of introducing it. The workshop presented geographical perspectives and experiences on implementing the CCC from Colombia, the United States and Europe, as well as professional perspectives from hygienists, students and policymakers. The workshop then considered the future of the CCC and the roles of Interprofessional Education, Technology, Global Networking and Assessment in a Global Context in 4 breakout groups. Having had reports back and plenary discussion, it was concluded that the caries world has made good progress towards a "futuristic" curriculum with parallel development of a comprehensive, preventive and tooth-preserving caries management system-ICCMS ${ }^{\mathrm{TM}}$. The implementation challenge is now to share even more effectively in order to have these developments more widely accepted and adopted worldwide.
\end{abstract}

\section{KEYWORDS}

caries management, caries risk assessment, cariology, curriculum, dental caries, Dental Education

\section{1 | INTRODUCTION}

This study reports on the full-day workshop "The Shape of The Future of Dental Education for Dental Caries-and how we get there" held immediately prior to the May 2017 ADEE/ADEA/King's College London meeting "Shaping the Future of Dental Education." The aims of the workshop were to understand the important role of

†See Appendix Group membership an up-to-date curriculum on dental caries for all dental (and other) professionals, with a focus shift towards more awareness of the caries process, the caries balance and preventive, as well as surgical methods, of caries care/treatment.

The scope of the day was truly global, although with an emphasis on the European and US contexts. The work being undertaken in this area has shifted to focus on implementation of what we have, as opposed to the previous pattern of endlessly seeking to re-invent the wheel. The workshop examined the Past-exploring what has 
happened so far in the journey towards an international cariology curriculum; the Present-outlining what the cariology teaching and wider landscape looks like today; and the Future-determining not only what should the future of caries education look like, but also exploring how we get there.

\section{1 | The caries process and caries balance}

The understanding of the basic, clinical and public health science underpinning dental caries has improved over the last decades, and comprehensive reviews, summaries and commentaries are available. ${ }^{1,2}$ Caries is now understood as a biofilm-mediated, sugar-driven, multifactorial, dynamic disease that results in the phasic demineralization and remineralization of dental hard tissues. The balance between pathological and protective factors influences the initiation and progression of caries. This interplay between factors also underpins the classification of individuals and groups into caries risk categories, allowing an increasingly tailored approach to care. ${ }^{1}$

\subsection{The European Core Curriculum in Cariology}

A standardised, evidence-led Core Curriculum in Cariology (CCC) was developed jointly and systematically by ORCA and ADEE, starting in 2010. The process was carefully constructed to build consensus $^{3}$ and took place after a Europe-wide survey of Dental Schools had validated both the need and demand. ${ }^{4}$ The final curriculum which emerged from a comprehensive workshop held in Berlin was published $^{5}$ in an open-access Supplement of this Journal, along with individual papers from each of the 5 Curriculum "Domains": The knowledge base; Risk Assessment, Diagnosis and Synthesis; Decision Making \& Preventive Non-Surgical Therapy; Decision Making \& Surgical Therapy; and Evidence-based Cariology in Clinical $\&$ Public Health Practice.

\section{3 | ICCMS ${ }^{\mathrm{TM}}$-International Caries Classification and Management System}

At the same time, the ICDAS-International Caries Detection and Assessment System-Foundation was evolving to develop its own holistic caries management tool-the International Caries Classification and Management System-ICCMS ${ }^{\text {TM }}$. The focus of this activity has always been multifaceted across the 4 areas of Education, Practice, Public Health and Research.

The "Caries risk assessment, diagnosis and synthesis" Domain of the European CCC mapped across the ICDAS continuum of caries to link lesion severity and activity to clinical decision-making. ${ }^{6}$ This scale of the continuum of caries was based on research evidence linking the pathology, diagnosis and logical management of caries, ${ }^{7,8}$ which was built into ICCMS ${ }^{\mathrm{TM}}$ as a System for staging of the caries process with both clinical and radiographic assessments and enabling dentists to manage the disease with caries management pathways that preserve dental tissues and promote oral health. ${ }^{9,10}$ The System incorporated consensus views from an international group of educators, researchers and practitioners ${ }^{11}$ and has been streamlined for easy adoption in its latest ICCMS ${ }^{\text {TM }}$ "4D" model. ${ }^{1}$

The ICCMS ${ }^{\mathrm{TM}}$ goals for caries management are as follows:

- To prevent new lesions from appearing

- To prevent existing lesions from advancing further

- To preserve tooth structure with:

- Non-operative care at more initial stages, and

- Conservative operative care at more extensive caries stages whilst managing risk factors and recalling patients at appropriate intervals, with periodic monitoring and reviewing.

Together, the CCC and ICCMS ${ }^{\mathrm{TM}}$ can provide a basis for researchled education supported by the philosophical shift towards Minimally Interventive - Restorative Care (MI-RC), which is now being advocated by King's College London. ${ }^{12}$ This allows us to fulfil a long-held desire to educate dental graduates to be both oral health physicians and surgeons. ${ }^{13}$ At King's College London, there is also an emphasis on equipping all the students to be able to contribute to Service to Society in order to make the world a better place as part of the University-wide Vision. ${ }^{14}$ Community projects and volunteering around caries prevention throughout the life-course lend themselves well to this type of activity.

\section{2 | THE CURRENT SITUATION}

The workshop reported on what has been achieved on a global basis by many individuals and groups building on these initiatives. The CCC has been, or is currently being, localised in a number of places around the world and has, in some countries, been successfully implemented The workshop presented geographical perspectives and experiences on implementing the CCC from Colombia, the United States and Europe; as well as professional perspectives from hygienists, students and policymakers.

\subsection{The Colombian perspective}

- Building on an extensive consultation process and working with the ACFF (Alliance for a Cavity-Free Future) Chapter, Deans and Educators, local adjustments were made to the European framework to make it more workable within Colombian academic and health systems. ${ }^{15}$

- A collective consensus from the country's 26 dental schools was reached on the new guidelines for cariology teaching for undergraduates and the paradigm shift towards a more preventive care focus.

- ICCMS $^{\mathrm{TM}}$ documentation has been translated into Spanish and is used broadly alongside curriculum documents within the country.

- Student engagement through national competitions has been found to be a very positive influence. 


\section{2 | The US perspective}

- Once again, building on an extensive consultation process and working with those who had developed the CCC in Europe and localised it in Colombia, an enthusiastic group from ADEA involved large numbers of US Schools and held a localisation Workshop and a Symposium at the ADEA meeting in Boston in 2015.

- The Core Cariology Curriculum framework for use in US Dental Schools was published in the Journal of Dental Education in June $2016 .{ }^{16}$

- This process also uncovered a significant gap in the US core competencies for graduates, where caries management strangely was not a visible requirement. It has been recommended that the core competencies for graduates are now rewritten to include appropriate caries detection, assessment and management skills.

- The process of implementing the CCC is underway, but there is a long way to go and take-up is variable. It is hoped that the formation of the American Academy of Cariology should accelerate adoption, as will the Canada-US Chapter of the ACFF supporting other health professionals.

\section{3 | European perspective}

- Focusing on dental education experiences in Portugal, it was noted that there is considerable interest in an increase in caries education for undergraduates. However, in some other countries implementation has been slower than expected.

- Some reasons behind the lack of implementation progress across Europe were highlighted. These included the following:

- Lack of understanding regarding the potential cost-effectiveness of prevention (on a political level).

- Perceived abundance of competing diagnostic systems and tools.

- Lack of understanding by Universities of how cariology impacts each area of teaching.

- The established caries management habits of current dental practitioners.

- It is believed that what may be useful in combatting this is the creation of a comprehensive document showing the benefit of ful adoption for both education and public health and policy groups.

- Translations of curriculum documentation into more languages would also assist locally and would help to identify appropriate key persons to assist with broad European CCC introduction at National and Faculty levels.

\section{4 | Hygienists perspective}

- National competency requirements for hygienists differ significantly within Europe, as do the requirements placed on them in their roles and the degree to which team dentistry is embraced.

- A call has also been made for the redefinition of the role of the dental hygienist to better suit a multiprofessional approach to dental care.

- Since 2015, the European Dental Hygienists Federation have been working on a harmonising hygienist education across Europe, a system which has already been approved by many governmental bodies.

- Hygienists are looking keenly for the creation of a "Common Educational Framework" (CEF) for caries.

\section{5 | Student perspective}

- Students tend to be very interested in prevention and minimally interventive dentistry.

- It has been suggested that a unified European (or global) assessment system would be welcomed as there is still a distinct lack of harmonisation across teaching methods, curriculum content and student assessment standards.

- The literature used in dental schools is often outdated, and the lack of translations available is a huge barrier to many dental schools in utilising the most up-to-date work, especially in countries with lower levels of English language usage.

- Prevention and preventive strategies should be taught throughout the undergraduate course, with specific, detailed, early integration of material for all students.

\subsection{Political and policy perspective}

- The discussion around updating the way cariology education is approached is very timely due to the progress with the Minamata Convention and ratification of the Treaty giving it legal force.

- When people think about dentistry, they traditionally think of restorative or invasive treatment by a dentist. The shift needed is for them to see that dental care also involves the whole dental (and even wider, health) workforce.

- Understanding the context of the world we are trying to influence is key in this battle, and we need to be realistic regarding expectations of what can be achieved and by when.

- Utilising universal indicators and centralising data is a key way of ensuring wider understanding within the discussions.

- Change can happen, it just needs to be influenced in the right way so that what at the moment seems radical can quickly become the norm.

- Interactions with policymakers and others around dental caries should include references to understanding the economic value of cavity prevention, the importance of prevention-based payment systems, better equipping the dental and wider healthcare workforce with educational materials on leading-edge prevention and shifting public and industry behaviours towards caries prevention. ${ }^{17}$ 


\section{7 | The role of electronic health records in caries education and caries care}

- After a long wait, comprehensive health records software for Education and Practice settings is now available to support a more holistic approach to oral health record keeping whilst also providing opportunities for research through collaboration.

- ICDAS caries staging has been integrated, offering the chance to classify lesions from severity stages 0-6 rather than just "yes" or "no"-carious or sound. In addition, lesions can be classified as active or inactive.

- More user-friendly software is the key to getting people to use systems-it needs to both be easy to use and suit the record-keeping requirements and preferences of users.

- If we can create a universal health record system, it would be beneficial for all healthcare practices and would allow us to offer holistic patient care inside and beyond dentistry.

- For some years, both dental students and dental practitioners have identified lack of software functionality as a key barrier to adopting more preventive care models and making monitoring lesions over time feasible in either a busy teaching clinic or dental practice a reality.

- Further development of user-friendly software packages to support both education and preventive clinical practice and longterm caries care with systems like ICCMS ${ }^{\mathrm{TM}}$ is a priority.

The workshop then considered the future of the CCC and the roles of Interprofessional Education, Technology, Global Networking and Assessment in a Global Context in 4 breakout groups which reported back to a plenary session. The key messages from the breakout groups are each illustrated by a Figure and a summary below.

\section{3 | INTERPROFESSIONAL EDUCATION AND CARIES}

Figure 1 shows the "ACFF Caries Puzzle"; which joins up the many interprofessional perspectives needed for caries prevention and control. In order to be effective in preventing cavitated caries, students have to learn that there is an important interplay between nutrition, education, behaviour change, cariology science, Public Health policies, clinical practice, a systematic approach to preventive caries management, working with other health professionals, the public, patients and others.

Other key points to emerge from the discussions were as follows:

- Education on the interprofessional approach to dental care should start from the first day of everyone's training; students are often unaware of the true nature of the work they are training to do. More practical steps should be put in place to allow for "real-world" training, which can interact with patients and also link
ACFF Caries Puzzle: Interprofessional Perspectives

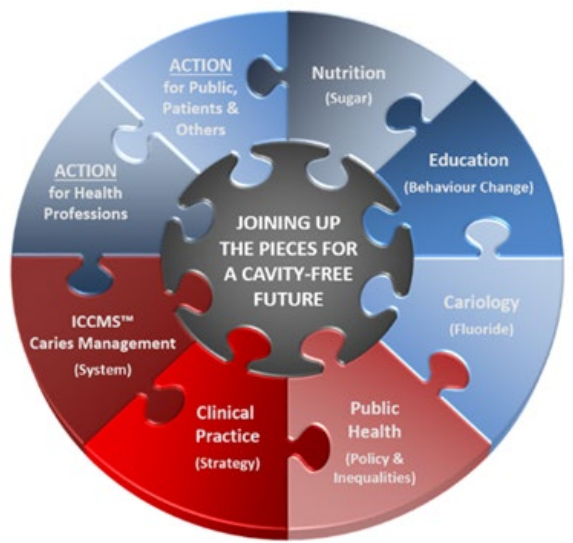

FIGURE 1 The ACFF Caries Puzzle: joining up interprofessional perspectives of cavity prevention [Colour figure can be viewed at wileyonlinelibrary.com]

to community and Service for Society settings.

- Educators need to be clear what the training programmes are trying to achieve by these activities. They should be labelled as "collaborative practice" in order to instil in students the importance of the collaborative workforce and make it "the norm."

- It is important to understand the questions that the other professions have around oral health and caries when assessing what we should be teaching; both to them and to dental practitioners. We need to teach all dental and healthcare professionals what they want or need to know if the team is to be truly functional as interprofessional.

- It was suggested that we should look within Universities at the possibility of pooling some basic science education together to reduce duplication of teaching. Creating cross-professional lectures would help students realise the interplay between their disciplines, but there have been challenges in delivering such a vision.

- Curriculum development could or should potentially have a community aspect to it. The group questioned whether we could ever get to a point where patients have a say in how their health workers are trained.

- The main barriers to truly integrated teaching were perceived to be the time and cost of overhauling and restructuring complex educational systems.

- It may be difficult to get buy-in for this "out-of-the-box" thinking, as in many countries it does not fit within any traditional dental education "box."

\section{4 | GLOBAL NETWORKING AND CARIES}

Figure 2 shows the cover of the ICCMS ${ }^{\mathrm{TM}}$ Guide for Practitioners and Educators. This is an excellent example of existing Global Networking in Cariology education. This comprehensive consensus Guide was produced by the Global Collaboratory for Caries Management 


\section{$I^{C} C^{T M}$ \\ CARIES MANAGEMENT

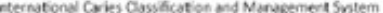 \\ ICCMS $^{\mathrm{TM}}$ Guide for Practitioners and Educators}

Nigel B. Pitts, FRSE BDS PhO FDS RCS (Eng) FDS RCS (Edin) FFGDP (UK) FFPH'

Amid I. Ismail, BDS, MPH, Dr. PH, MBA'

Stefania Martignon, BDS, PhD

Kim Ekstrand, BOS, Pho'

Gail V. A. Douglas, BMSC, BDS, MPH, FDS, PhD, FDS (DPH) RCs

Christopher Longbottom, BDS, PhD'

Contributing co-authors*

Christopher Deery, University of Sheffleid, UK

Hafsteinn Eggertsson, Wilamette, Eugene, USA

Roger Elwood, University of Manchester, UK

Juliana Gomez, University of Manchester, UK

Justine Kokker, University of lowa, USA

David Manton, University of Melboume, Austral:

Michael McGrady, University of Manchester, UK

Peter Rechmann, University of Calfomia San Francisco, USA

David Ricketts, University of Dundee, UK

Woosung Sohn, Boston University, USA

Van Thompson, Kings College, London, UK

Svante Twetman, University of Copenhagen, Denmark

Robert Weyant, University of Pittsburgh, USA

Andrea Ferreira Zandona, University of North Carolina, USA

Domenick Zero, Indiana University School of Dentistry, USA

On behalf of the Participating Authors of the International Caries Classification and Management System (ICCMS ${ }^{\mathrm{n}}$ ) Implementation Workshop, held June 2013**

\section{December 2014}

"King's College London Dental Instutue, Dental Innovation and Translation Centre, Guyss Hosptal, London, UK

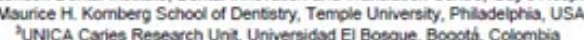

University of Copenhagen, Denmax.

"School of Dentistry, Universiny of Leeds, UK

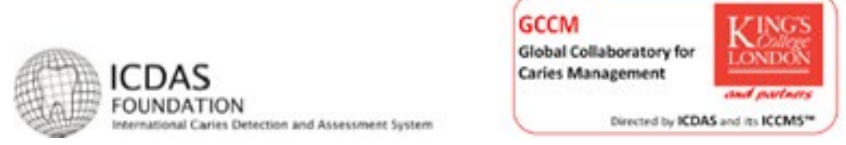

FIGURE 2 The ICCMS ${ }^{\text {TM }}$ Guide for Practitioners and Educators, produced by the Global Collaboratory for Caries Management coordinated by King's College London ${ }^{11}$ [Colour figure can be viewed at wileyonlinelibrary.com]

coordinated by King's College London. It is the result of 75 international educators and researchers coming together to define best practice in caries prevention and clinical caries management.

Other key points to emerge from the discussions were as follows:

- It is much easier now than it was even 20 years ago to create global networks. Moving forward, we need to identify the most effective ways to use technological systems (such as shared platforms) to share information and best practice in curriculum creation and guiding implementation.

- When looking at how and where to share information, we need to make sure we are considering not just educators and dental clinicians. It is equally important to be assisting in networking nutritionists, public health professionals, primary care practitioners and others if we are to ensure a comprehensive cross-professional approach to care.

- In ensuring accessibility of information, we need to remember to always try to use plain messaging for global comprehension, and develop strong, clear communication using simpler language than we may be used to. Early translation of materials into a range of languages will also play a key role in ensuring messages can be shared broadly.

- We should also include governments, NGOs, charities, patient advocacy groups and companies in the distribution plan, as they can all play an important role in ensuring the longevity of any initiative at scale.

\section{5 | NEW TECHNOLOGY AND CARIES}

Figure 3 shows a page from a Dental Practice/Education software screen from ICE Health Systems (www.icehealthsystems.com), which allows the student or dentist to rapidly record both the stage of lesion severity and the lesion activity status according to the ICDAS classification (left side of image). The data are then automatically added to an odontogram (right side of image) and treatment planning module (bottom of image) in order to maximise speed, reduce the number of clicks and minimise errors. This is the type of information needed to support modern, preventive, tooth preserving, caries care.

Other key points to emerge from the discussions were as follows:

- New technology will play a vital role in enabling and ensuring global, interprofessional approaches to care are possible and successful.

- We need access to systems that communicate across professions (schools, health teams, etc.), and we all need to all speak the same "language." If you speak the same language, pooling data is much easier. Lack of common, harmonised data standards have in the past undermined attempts to deliver effective evidence-based care as well as frustrated attempts to use multiple sites for longitudinal research, quality improvement and economic analyses.

- Younger generations should be very useful in the development of this, as students are much "savvier" with how they would want to use technology within their practice.

- This approach can also encourage interest from non-dental groups, which would allow the programmes to expand into other areas of health care and provide a more holistic approach to care.

- It was felt that there is much to be said for what larger, established initiatives (such as Google) might offer in this field. The idea of linking companies for cross-purposes is not new, although commercial barriers may be problematic.

- There is currently a desire to teach evidence-based dentistry; however, the capabilities of the technology we now have has in some ways overtaken the traditional evidence we currently can offer in order to do so. There is a need to enhance critical thinking and approaches to innovation that safeguard patients whilst allowing progress and ongoing evaluation and outcome assessment.

- Technology should be used as a supplement to teaching-we need to equip students to know when and how to ask the right questions and then offer the resources to assist them in finding the right answers. 


\section{EHR Examples (ICE) and Dental Caries}
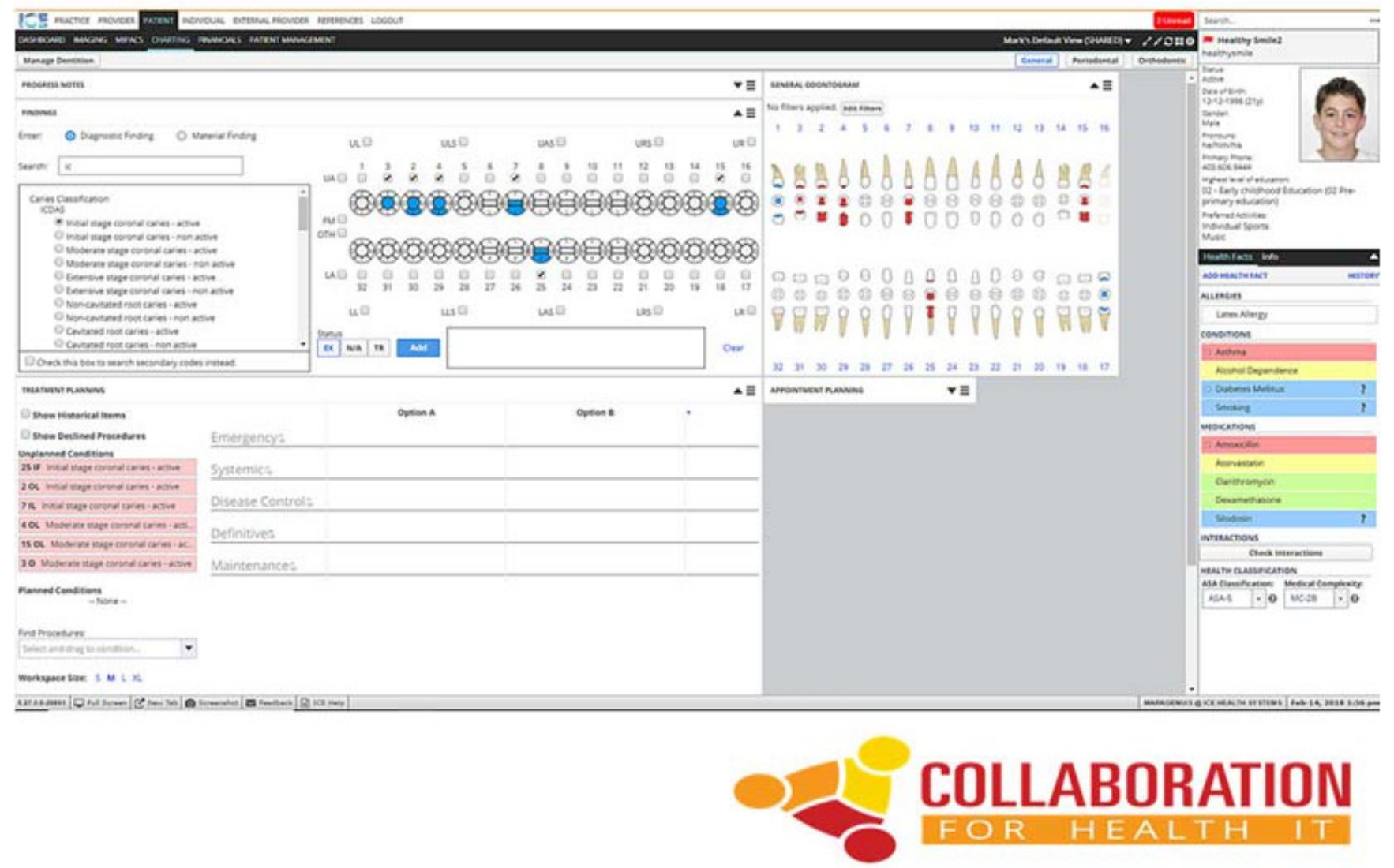

FIGURE 3 Shows a page from a Dental Practice/Education software screen from ICE Health Systems (www.icehealthsystems.com) which allows the student or dentist to rapidly record both the stage of lesion severity and the lesion activity status according to the ICDAS classification (left side of image). The data are then automatically added to an odontogram (right side of image) and treatment planning module (bottom of image) in order to maximise speed, reduce the number of clicks and minimise errors [Colour figure can be viewed at wileyonlinelibrary.com]

- A recent caries example of eLearning enhanced material on dental caries is a caries module in the Biomedical Foundations through Clinical Cases (BFCC) series on the Healthcare Learning Schools Network. ${ }^{18}$ This links the basic science underpinning cariology with some clinical case scenarios and helps to address the problems of Dental Schools without specific teaching expertise in such areas.

- There are opportunities which will emerge to use big data to understand caries and caries care better, as well as to use this type of information to inform and empower patients. As in other fields, technology may dramatically alter the caries landscape in the years to come.

\section{6 | ASSESSMENT IN A GLOBAL CONTEXT AND CARIES}

Figure 4 shows a version of a flow chart from an ICCMS "M "4D" caries management plan for personalised caries prevention, control and tooth-preserving operative care. ${ }^{1}$ It is important that the assessment of students in the area of caries care reflects the full scale of this intellectual and clinical task and does not just focus on (any) operative intervention required (as is frequently the case in many Dental Schools at present).

Other key points to emerge from the discussions were:

- There should be a more universal baseline for dental education across the board, not just for clinical dentists, particularly as there is a large section of the dental workforce choosing to work internationally.

- We need to assist practitioners in speaking the same dental language. Common standards are difficult to achieve but are important and enabling.

- There should be a grading system to assess the caries competency of new dentists which is globally calibrated to offer a rating which can be transferrable and understandable wherever they decide to work. This system should assess clinical decision-making and 


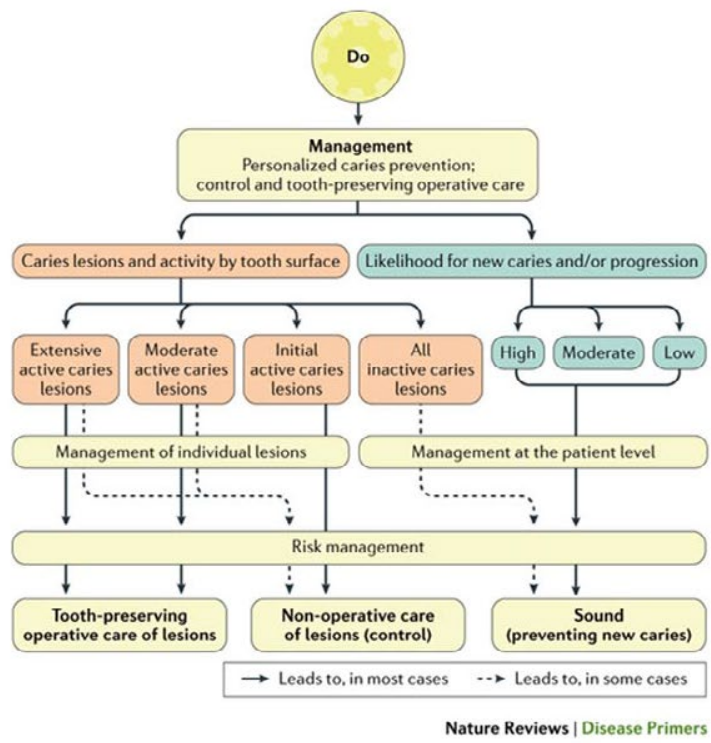

Pitts, N. B. et al. (2017) Dental caries Nat. Rev. Dis. Primers doi:10.1038/nrdp.2017.30

FIGURE 4 Shows a flow chart from an ICCMS ${ }^{\text {TM }}$ 4D caries management plan for personalised caries prevention, control and toothpreserving operative care (Reproduced with kind permission from Nature Reviews Disease Primers ${ }^{1}$ ) [Colour figure can be viewed at wileyonlinelibrary.com]

also advise as to any additional skills or training suggested for the individual to be able to work in practice.

- Assessment should be continuous and longitudinal rather than cross-sectional. A syllabus of topics would not be covered and assessed in a specific order, but with the creation of a whole monitoring process offering assessment in clinical competencies across the many years of training. This would offer the chance to see the students develop and target areas of need, as well as to extend their skills when specific core areas had been mastered.

- We should be looking at working as an interprofessional collective to develop a holistic approach to assessment, using a network of specialists to ensure our approach is not narrow.

- There was a suggestion from some that independent assessors could be brought in to assess students' competency. This would allow standardised, subjective evaluation of each student. Two key requirements of this would be the creation of a system to calibrate the skills of the assessors and the logistical comprehension of how this could translate to a global scale programme, which would be necessary if it were to be effective. The logistical and economic barriers to introducing such a system were not underestimated.

\section{7 | SUMMARY AND RECOMMENDATIONS}

- We need a paradigm shift towards ethical team-delivered oral healthcare and caries care.
- We need to be aware of the breadth and diversity of the issues around implementing the Core Caries Curriculum we already have.

- Oral health and particularly caries do link strongly to general health through the sugar agenda and obesity. We need to view the subject of caries prevention in the context of wider health and ensure that students are well equipped to understand the broader perspective as well as the clinical dental focus on individual patients.

- We should ensure that students and staff are equipped with the latest leading-edge diagnostic, preventive and surgical skill sets, and that they know how and when to use them, and when not to.

- We need to be aware of how what we are teaching in dental schools translates into real-world situations for graduates and help them transition.

- The use of Minimally Interventive Restorative Care dentistry encourages integration throughout the dental team, as the work of all members is important in the process.

- There are examples of sustainable and profitable business/workforce models utilising this structure which should be shared more widely.

\section{8 | CONCLUSION}

Following the range of presentations across the day, the breakout group focussed sessions and reports back to a plenary discussion, 
it was concluded that the caries world has made good progress towards a "futuristic" curriculum with parallel development of a comprehensive, preventive and tooth-preserving caries management system-ICCMS ${ }^{\mathrm{TM}}$. The implementation challenge now faced is to share our resources even more effectively in order to have these developments more widely accepted and adopted worldwide.

\section{ACKNOWLEDGEMENTS}

The authors are indebted to all members of the Shaping the Future of Dental Education Cariology Group for their contributions to the presentations, breakout groups and discussions at the workshop. We also wish to fully acknowledge the important contributions made over a number of years by: Andreas Schulte, Marie Charlotte Huysmans, Christian Splieth and Wolfgang Buchalla in driving the ORCA side of the development of the European Core Curriculum in Cariology for undergraduate dental students, Damian Walmsley's contribution with others from the ADEE side, all of those contributing to the development and refinement of ICCMS ${ }^{\mathrm{TM}}$, those working in ACFF Chapters worldwide and colleagues at King's College London Dental Institute. We also acknowledge financial support from a range of Companies who generously supported the development of the CCC and ICCMS ${ }^{\mathrm{TM}}$ as well as Colgate, who kindly supported this specific Workshop with an unrestricted grant.

\section{REFERENCES}

1. Pitts NB, Zero D, Marsh P, et al. Dental caries. Nat Rev Dis Primers. 2017;3: https://doi.org/10.1038/nrdp.2017.30 .

2. Pitts NB, Zero D. FDI Word Dental Federation-Colgate Caries Prevention Partnership: White Paper on Dental Caries Prevention and Management [internet]. Geneva: FDI; 2016. www.fdiworldental.org/media/93783/2016-fdi_cpp-white_paper.pdf. Accessed February, 2018.

3. Schulte AG, Pitts NB. First consensus workshop on the development of a European Curriculum in Cariology. Eur J Dent Educ. 2011;15(Suppl. 1):1-2.

4. Schulte AG, Buchalla W, Huysmans MC, et al. A survey on education in cariology for undergraduate dental students in Europe. Eur $J$ Dent Educ. 2011;15(Suppl. 1):3-8.

5. Schulte AG, Pitts NB, Huysmans MC, Splieth C, Buchalla W. European Core Curriculum in Cariology for undergraduate dental students. Eur J Dent Educ. 2011;15(Suppl. 1):9-17.

6. Pitts NB, Melo P, Martignon S, Ekstrand K, Ismail A. Caries risk assessment, diagnosis and synthesis in the context of a European Core Curriculum in Cariology. Eur J Dent Educ. 2011;15(Suppl. 1):23-31.

7. Ekstrand KR, Ricketts DN, Kidd EA. Occlusal caries: pathology, diagnosis and logical management. Dent Update. 2001;28(8):380-387.

8. Kidd EA, Banerjee A, Ferrier S, Longbottom C, Nugent Z. Relationships between a visual ranked caries scoring system and two histological validation techniques; a laboratory study on occlusal and approximal carious lesions. Caries Res. 2003;2003(37):125-129.
9. Pitts NB, Ekstrand KR. International Caries Detection and Assessment System (ICDAS) and its International Caries Classification and Management System $\left(\right.$ ICCMS $\left.^{\text {TM }}\right)$ - methods for staging of the caries process and enabling dentists to manage caries. Community Dent Oral Epidemiol. 2013;41:e41-e52.

10. Ismail Al, Tellez M, Pitts NB, et al. Caries management pathways preserve dental tissues and promote oral health. Community Dent Oral Epidemiol. 2013;41:e12-e40.

11. Pitts NB, Ismail AI, Martignon S, Ekstrand K, Douglas GV, Longbottom C. ICCMS ${ }^{T M}$ Guide for Practitioners and Educators [internet]. London: Global Collaboratory for Caries Management; 2014. www.iccms-web.com/uploads/asset/592845add7ac8756944059. pdf. Accessed February, 2018.

12. Banerjee A. Minimum intervention - MI inspiring future oral healthcare? Br Dent J. 2017;223:133-135.

13. Pitts NB. Are we ready to move from operative to non-operative/ preventive treatment of dental caries in clinical practice? Caries Res. 2004;38:294-304.

14. King's College London (KCL). King's Strategic Vision 2029 [internet]. London: KCL; 2017. www.kcl.ac.uk/aboutkings/strategy/Kingsstrategic-vision-2029.pdf. Accessed February, 2018.

15. Martignon S, Marin L, Pitts NB, Jácome-Liévano S. Consensus on domains, formation objectives and contents in cariology for undergraduate dental students in Colombia. Eur J Dent Educ. 2014;18:222-233.

16. Fontana M, Guzmán-Armstrong S, Schenkel A, et al. Curriculum development of a Core Curriculum Framework in cariology for U.S. dental schools. J Dent Educ. 2016;80:705-720.

17. Pitts NB, Grant J, Hinrichs-Krapels S, Mazevet ME. Towards a CavityFree Future: How Do We Accelerate a Policy Shift Towards Increased Resource Allocation for Caries Prevention and Control? [internet]. London: The Policy Institute at King's; 2017. www.kcl.ac.uk/sspp/ policy-institute/publications/Towards-a-cavity-free-future.pdf. Accessed February, 2018.

18. Healthcare Learning Schools Network. Biomedical Foundations through Clinical Cases: BFCC Demonstration [internet]. 2015. www. youtube.com/watch?v=IfNvl9DALQI. Accessed February, 2018.

How to cite this article: Pitts NB, Mazevet ME, Mayne C; On behalf of the Shaping the Future of Dental Education Cariology Group. Shaping the future of dental education: Caries as a case-study. Eur J Dent Educ. 2018;22(Suppl. 1):30-37. https://doi.org/10.1111/eje.12345

\section{APPENDIX - SHAPING THE FUTURE OF DENTAL EDUCATION CARIOLOGY GROUP MEMBERS}

Avijit Banerjee (King's College London), Luka Banjsak (European Dental Students Association), Julian Fisher (THEnet), Margherita Fontana (University of Michigan, ACFF Canada/US Chapter), Mark Genuis (ICE Health Systems), Lynn Johnson (University of Michigan), Stefania Martignon (Universidad El Bosque \& King's College London, ACFF Colombia Chapter), Paulo Melo (University of Porto) and Yvonne Nyblom (European Dental Hygienists Federation, ACFF Pan-European Chapter). 